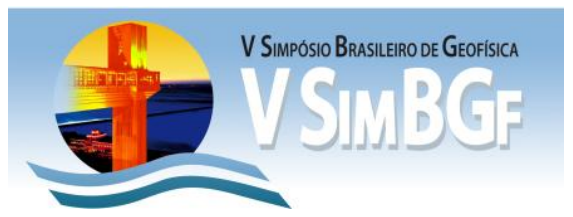

\title{
Identificação de interferências em grandes extensões por meio de GPR com georreferenciamento simultâneo do levantamento
}

Patrício José Moreira Pires, Universidade Federal do Espírito Santo.

José Tavares Araruna Júnior, Pontifícia Universidade Católica do Rio de Janeiro.

Copyright 2012, SBGf - Sociedade Brasileira de Geofísica

Este texto foi preparado para a apresentação no V Simpósio Brasileiro de Geofísica, Salvador, 27 a 29 de novembro de 2012. Seu conteúdo foi revisado pelo Comitê Técnico do V SimBGf, mas não necessariamente representa a opinião da SBGf ou de seus associados. É proibida a reprodução total ou parcial deste material para propósitos comerciais sem prévia autorização da SBGf.

\section{Resumo}

O presente trabalho apresenta um levantamento para identificações de interferências por meio da utilização do GPR, Ground Penetrating Radar. O levantamento foi realizado nas cercanias das pistas de pouso e de aterrisagem do Aeroporto Internacional do Rio de Janeiro - Galeão. O levantamento teve uma extensão total de 4368 metros lineares. Foram detectadas diversas interferências desconhecidas no cadastro existente de instalações da área. Entretanto, devido a grande extensão e da necessidade de se realizar o levantamento em um curto intervalo de tempo, dada às condições locais de pouso e aterrisagem de aeronaves, foi de fundamental importância à utilização de técnicas de georreferenciamento simultânea ao levantamento.

\section{Introdução}

A necessidade de melhoramentos e modernização do sistema de instalações eletroeletrônicas que margeia uma das pistas de pouso e aterrisagem do Aeroporto Internacional do Rio de Janeiro, Galeão, se fez necessário o levantamento cadastral de interferências na referida área. Trata-se de uma área de trabalho que tem fortes restrições de acesso devido a procedimentos operacionais e de segurança indispensáveis a atividade. O projeto a ser executado prever a escavação de uma vala retangular com dimensões aproximadas de 1,0 metro de largura por 1,5 metros de profundidade. Nesta vala serão instaladas diversas tubulações para passagem de novas instalações eletroeletrônicas, como também a construção de caixas para inspeção e passagem das instalações. Por recomendações normativas da Infraero Empresa Brasileira de Infraestrutura Aeroportuária, todas as instalações circunvizinhas às pistas de pouso e aterrisagem devem ser subterrâneas. Dada a necessidade da realização da referida obra, tal serviço será realizado com o aeroporto em pleno funcionamento. O cadastramento das interferências faz-se necessário e importante para que sejam minimizados possíveis acidentes que possam ocasionar o rompimento de cabos e tubulações existentes na área.

A adoção de uma técnica não destrutiva tipo GPR para o referido levantamento, faz com que esse seja realizado sem a necessidade de mobilização de grande número de pessoas e equipamentos, o que torna uma condição favorável a realização deste levantamento. Experiências bem sucedidas acumuladas nos últimos anos pelo Laboratório de Monitoramento e Mitigação Ambiental LAMMA, da Pontifícia Universidade Católica do Rio de Janeiro, relatadas por Araruna Jr. et al., 2002, Souza et al., 2006 e Pires et al, 2011, torna a adoção desta técnica de investigação competitiva e eficiente. Rodrigues \& Porsani, 2006 também descrevem que há um consenso no meio técnico que as investigações não destrutivas, que empregam métodos geofísicos, podem atuar de uma maneira eficaz no levantamento de informações da subsuperfície.

O presente trabalho apresenta uma aplicação prática de cadastramento de interferências com uso do Ground Penetration Radar, GPR, entretanto das às peculiaridades do local investigado, as quais sejam, tempo reduzido para investigação, grandes extensão do levantamento e dificuldades de acesso ao local, torna a utilização do sistema de posicionamento global, GPS, acoplado ao GPR, simultaneamente a realização da investigação, fez com que o rendimento do trabalho de campo, bem como a exatidão das interferências detectadas fossem otimizadas.

\section{Metodologia}

O levantamento geofísico foi executado empregando o Ground Penetration Radar, GPR, da marca MALA modelo Ramac. O equipamento consiste de uma unidade de aquisição e controle instalada em uma mochila, ou em carro plástico, onde os sinais das ondas emitidos e recebidos são transferidos para um monitor que permite a visualização dos sinais eletromagnéticos e 0 seu armazenamento em meio digital. O posicionamento das antenas foi realizado através de um odômetro que transmite os sinais eletromagnéticos a unidade de aquisição e controle, e por um sistema de posicionamento global geodésico da Marca Ashtech modelo Promark II, que permite através do pacote computacional GPS Mapper realizar o posicionamento das sondagens geofísicas no pacote computacional Google Earth.

A Figura 01 apresenta o conjunto utilizado para realização deste levantamento. Identifica-se nesta figura o carrinho plástico para montagem dos equipamentos empregados (i.e., ôdometro, unidade de aquisição, armazenamento e visualização de dados, antena blindada de $500 \mathrm{MHz}$, e GPS geodésico).

A frequência central de antena foi escolhida por propiciar uma boa penetração do sinal, possibilitando alcance superior a $2 \mathrm{~m}$, que era a cota prevista para o lançamento 
das tubulações. A antena por ser blindada minimiza os problemas associados à interferência de ruídos externos e interferências as instalações existentes.

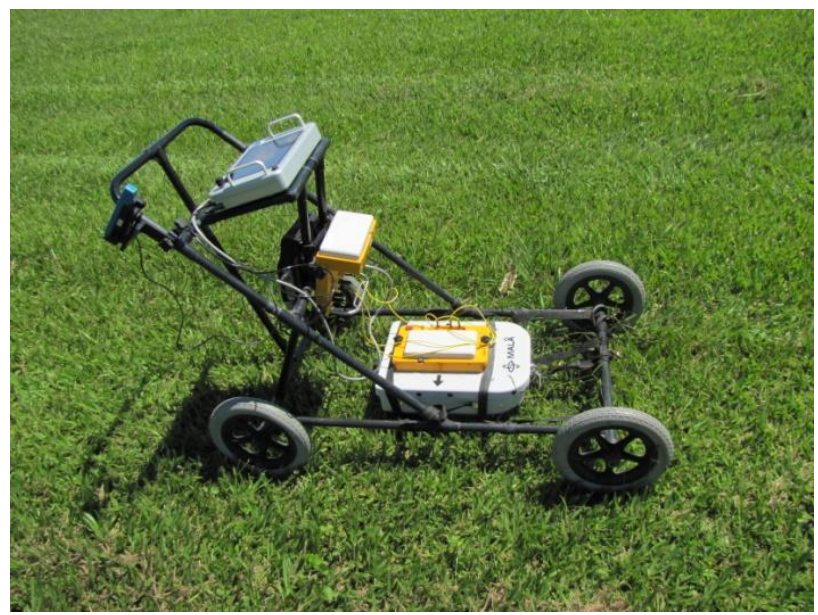

Figura 1 - Equipamento utilizado para o levantamento.

A aquisição de dados com o GPR foi realizada utilizandose o pacote computacional do monitor Mala modelo XV de aquisição e armazenamento de dados e, para os perfis, foram adotados os seguintes parâmetros:

- $\quad$ número de stacks (empilhamento) - automático;

- $\quad$ intervalo entre scans (traços) - 0,03m;

- frequência de amostragem - $6785 \mathrm{MHz}$

- velocidade de onda: $75 \mathrm{~m} / \mu \mathrm{S}$

Os dados adquiridos foram processados utilizando-se o programa RadExplorer ${ }^{\circledR}$. O processamento utilizou os seguintes filtros: filtro de correção do tempo zero, filtro de passa baixa e o filtro $D C$ removal.

A identificação das interferências foi facilmente detectadas e a sua localização foi representada no próprio radargrama por meio de recursos do programa RadExplorer. O posicionamento da antena foi realizado através de um odômetro que transmite os sinais eletromagnéticos a unidade de aquisição e controle, e por meio de um GPS acoplado ao GPR o que possibilitou, uma vez identificada determinada interferência no radargrama, obter a sua posição georreferenciada, coordenadas geográficas dos pontos identificados, como também foi possível localizar a seção do radargrama em imagens aéreas da área investigada.

O lançamento dos radargramas a imagens áreas é feito através do pacote computacional GPS Mapper ${ }^{\circledR}$, onde é possível visualizar o posicionamento das sondagens geofísicas no pacote computacional Google Earth.

A Figura 02 apresenta um exemplo do lançamento de uma seção da área investigada em uma imagem de satélite. A linha vermelha, em destaque na imagem, representa o alinhamento da seção realizada com 0 GPR.

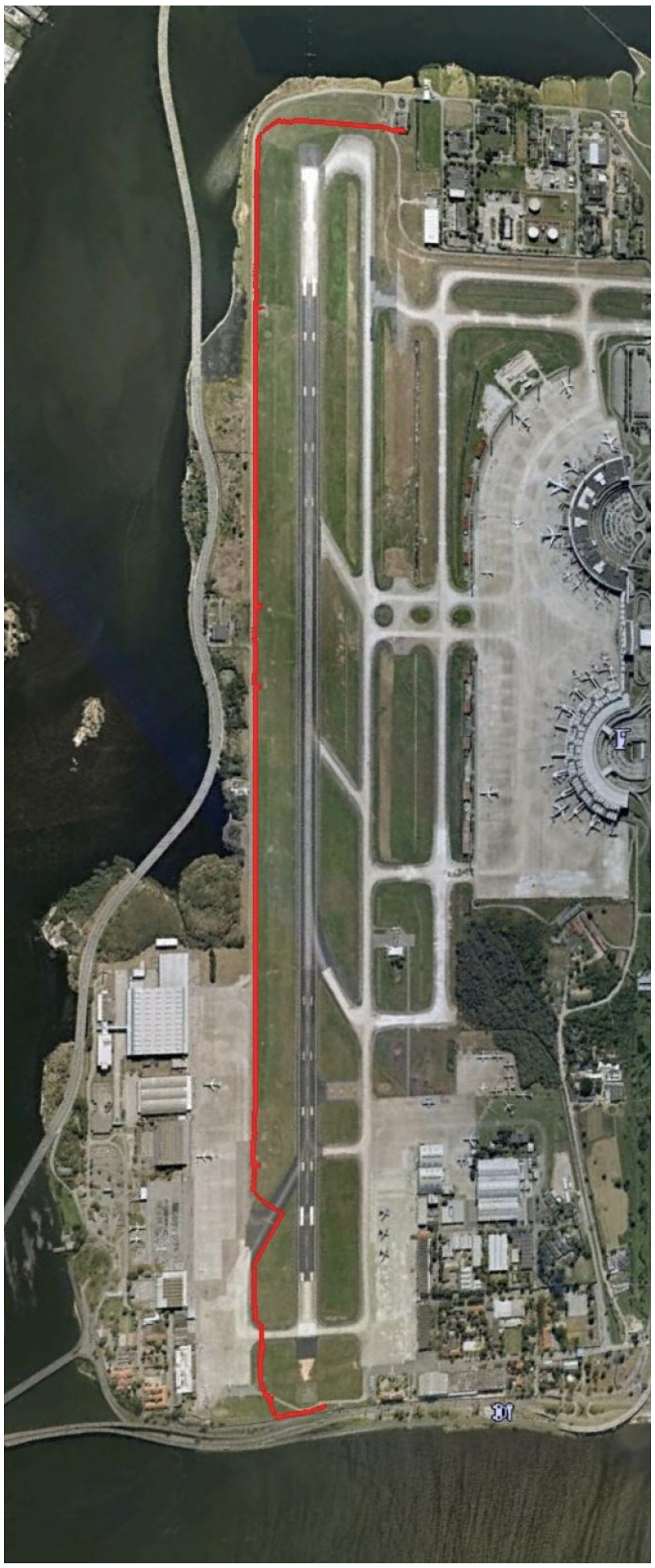

Figura 2 - Exemplo de lançamento de uma seção da área investigada em uma imagem de satélite. 


\section{Resultados}

A campanha de investigação geofísica foi realizada em 32 seções o que totalizou 4368 metros lineares de levantamento em 16 horas de levantamento. Todas as seções foram devidamente georreferenciadas simultaneamente ao levantamento e pós-processadas para interpretação dos radargramas.

A seguir são apresentados alguns exemplos de interferências detectadas.

A Figura 3 apresenta a localização na imagem aérea da seção geofísica 724, e a figura 4 apresenta o trecho desta seção na qual foram identificadas três interferências.

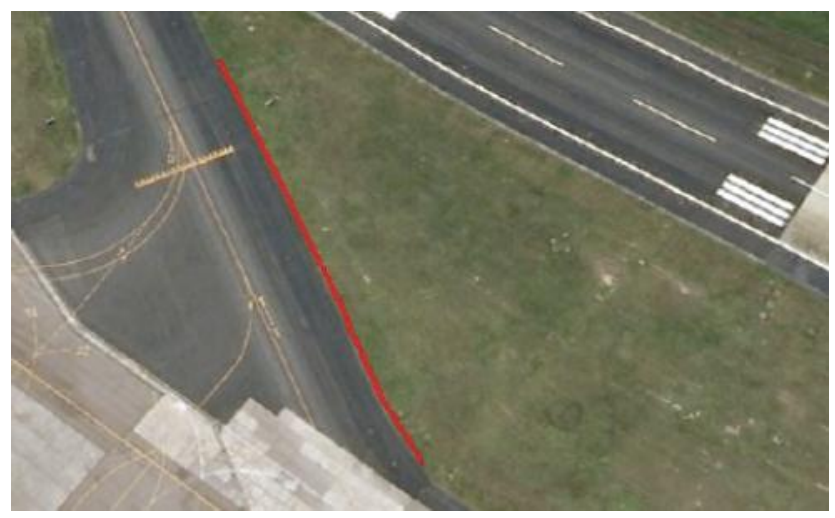

Figura 3 - Localização na imagem aérea da seção 724.

As interferências detectadas nesta secão corta transversalmente a pista de taxeamento que dá acesso a pista 33 de pouso e aterrisagem. Neste trecho foram detectadas diversas interferências, possivelmente associadas a antigas instalações pertencente ao antigo terminal do galeão localizado no entorno.

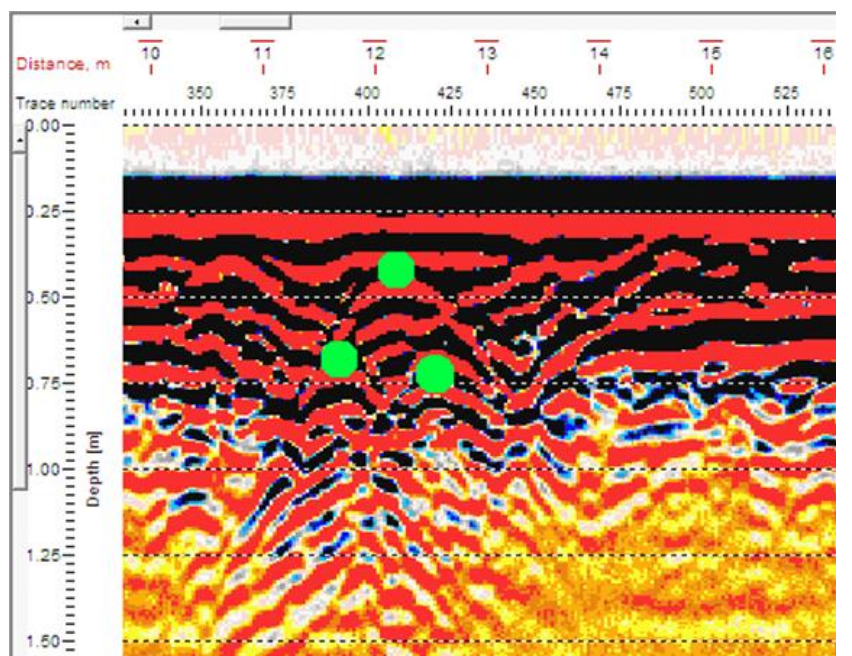

Figura 4 - Trecho entre 10 e 16 metros da seção 724.
A Figura 5 apresenta a localização da seção 698 na imagem aérea. Essa seção localiza-se próximo ao terminal de carga do aeroporto.

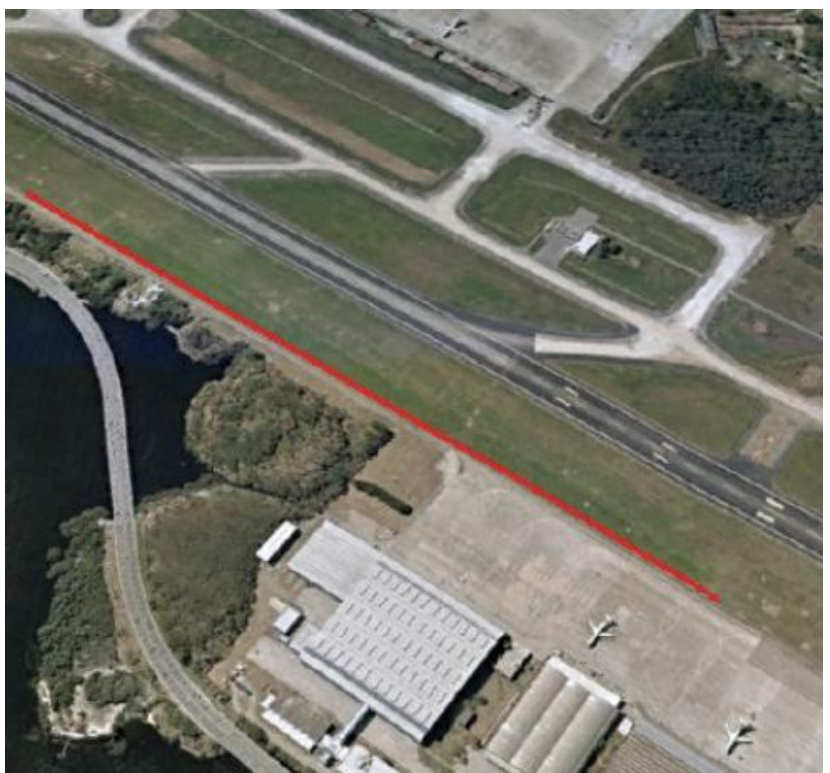

Figura 5 - Localização na imagem aérea da seção 698.

A Figura 6 apresenta duas interferências detectadas na seção 698 nos pontos situados a 1035 e 1038 metros do início da seção respectivamente. Observam-se, de acordo com a posição das interferências indicadas, que foram realizadas seções de grandes dimensões, o que foi facilitado pelo sistema de georreferenciamento. Eventualmente, interferências nítidas presente nos radargramas eram devidamente confirmadas, quando possível, em campo, ainda durante a fase de levantamento. As interferências apresentadas na seção 698, Figura 6, são tubulações de água existentes no local. As coordenadas geográficas dessas interferências detectadas são $22^{\circ} 49,585^{\prime} \mathrm{S}, 43^{\circ} 14,703^{\prime} \mathrm{O}$ e $22^{\circ} 49,586^{\prime} \mathrm{S}$ e $43^{\circ} 14,702^{\prime} O$ respectivamente. Ambas com elevação de 5 metros. As coordenadas dos pontos indicados foram determinadas durante a fase de processamento. 


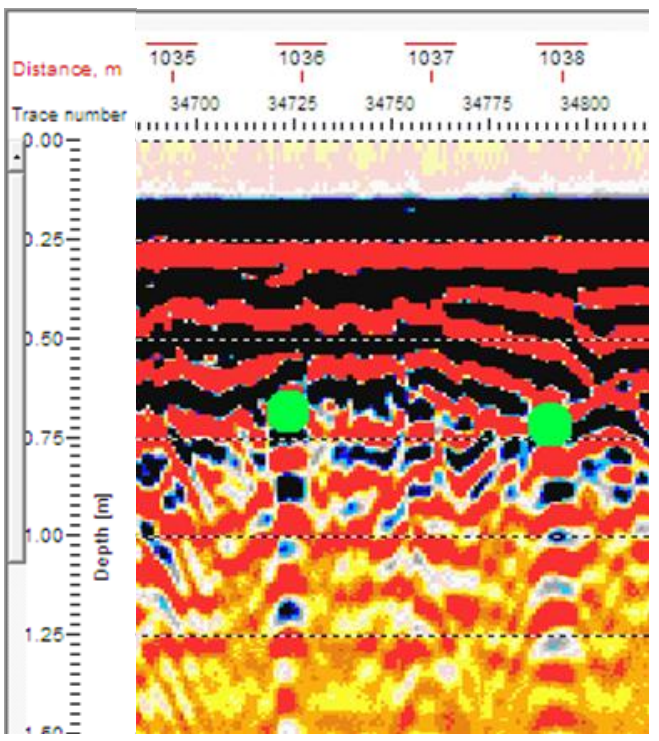

Figura 6 - Trecho entre 1035 e 1038 metros da seção 698.

$\mathrm{Na}$ tela de processamento dos radargramas é possível determinar as coordenadas dos pontos de interesse. A Figura 7 apresenta um exemplo da tela de processamento dos radargramas. Na Figura 8 observa-se um detalhe onde é possível verificar as coordenadas dos pontos de interesse na fase de processamento.

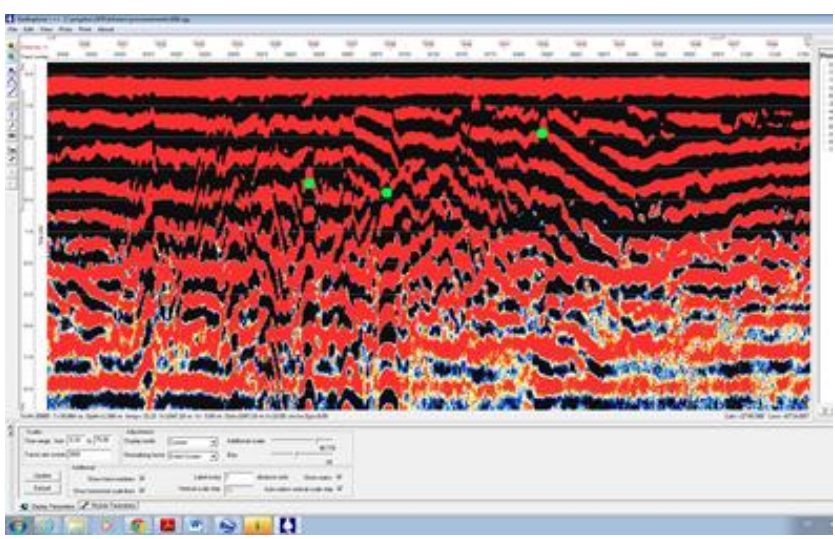

Figura 7 - Tela de processamento dos radargramas

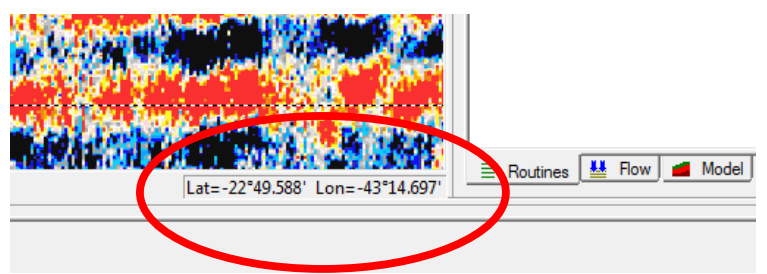

Figura 8 - Detalhe apresentado as coordenadas de um ponto na tela de processamento de radargramas.

\section{Considerações finais}

O levantamento com GPR realizado no Aeroporto Internacional do Rio de Janeiro, Galeão, atingiu resultados satisfatórios. Foi possível a identificação de diversas interferências na área de estudo o que será de fundamental importância para orientar os serviços de escavação a ser executado no local.

Tal levantamento foi realizado sem a necessidade de grandes mobilizações de equipamento e pessoal e realizado em um curto intervalo de tempo, dada à dimensão do levantamento.

As interferências foram facilmente identificadas graças à experiência acumulada pelo Laboratório de Monitoramento e Mitigação Ambiental - LAMMA, da Pontifícia Universidade Católica do Rio de Janeiro em trabalhos desta natureza, como relatado por Araruna et al., 2007. Entretanto, o local investigado trata-se de um aterro arenoso homogêneo, com nível d'água abaixo da cota de interesse, o que foi um facilitador para interpretação dos radargramas.

\section{Referências}

Araruna Jr. J.T., Nunes, C.M.O., Costa, A. e Vargas Jr, E.A. (2002). O emprego do radar de penetração (gpr) na detecção de elementos de fundação. Anais do XII Congresso Brasileiro de Mecânica dos Solos e Engenharia Geotécnica, São Paulo, pp. 135-146.

Araruna Jr.,J.T., Pires, P.J.M., Pilotto, D.L. e Amaral, C.P. (2007). Considerações acerca da empregabilidade do radar de penetração (gpr) na detecção de elementos enterrados em áreas urbanas. Anais do VII Congresso Brasileiro de Geotecnia Ambiental - REGEO2007.

Pires, P. J. M. \& Araruna Jr, J. T. (2011). The Use of Shallow Geophysics in Borrow Clayey Deposits Surveys in NorthEast Brazil. 12th International Congress of Brazilian Geophysical Society held in Rio de Janeiro, Brazil, August, 2011.

Rodrigues, S.I. e Porsani, J.L. (2006). Utilização do gpr para caracterizar tambores plásticos enterrados no sítio controlado de geofísico rasa do IAG/USP. Revista Brasileira de Geofísica, vol. 24, número 2, pp. 157-168.

Souza, M.M., Araruna Jr., J.T., Antunes, F.S. e Nunes, C.M.O. (2006). O uso do gpr para detecção de vazamentos de água. Estudo de caso: Parque Gráfico do Jornal O Globo - RJ. Anais do XIV Congresso Brasileiro de Águas Subterrâneas, pp. 1-15. 